\title{
Instrumento para atendimento às normas de transporte rodoviário de resíduos perigosos: Apoio aos gestores de sustentabilidade de unidades de saúde
}

\author{
Instrument for hazardous waste transport: Support for sustainability managers of health units
}

Instrumento para el cumplimiento de la normativa para el transporte por carretera de residuos

peligrosos: Apoyo a los gestores de sostenibilidad en los establecimientos sanitarios

Recebido: 29/06/2021 | Revisado: 04/07/2021 | Aceito: 07/07/2021 | Publicado: 09/07/2021

Ingrid Felizardo Chaves Cicca ORCID: https://orcid.org/0000-0002-1674-494X Universidade Federal Rural do Rio de Janeiro, Brasil E-mail: ingrid.cicca@gmail.com

Fabiola de Sampaio Rodrigues Grazinoli Garrido ORCID: https://orcid.org/0000-0001-5177-1241 Universidade Federal Rural do Rio de Janeiro, Brasil E-mail: fabiola_srg@yahoo.com.br

\begin{abstract}
Resumo
O objetivo desse trabalho foi propor um instrumento de gestão para os setores de sustentabilidade que desempenham suas atribuições dentro de unidades hospitalares no Brasil. Assumindo-se uma análise qualitativa da demanda de documentos e do conjunto de normas comuns ao cenário nacional, foi possível reunir os procedimentos em um checklist para unidades hospitalares. As mesmas são responsáveis desde a geração até a destinação final de resíduos. No entanto, como o trabalho de transporte e destinação é terceirizado, o presente instrumento poderá contribuir para a verificação e correção de possíveis inconformidades apresentadas pelas terceirizadas. Nas atividades de coleta e transporte externos de resíduos de serviços de saúde, observam-se entre os riscos as condições de acondicionamento para o transporte, carregamento e descarregamentos dos caminhões, risco de ocorrência de acidente rodoviário tombamento do caminhão, abalroamento etc. Assim, uma série de condições poderão ser impostas pelo órgão ambiental para concessão da licença ambiental ou de operação referente às atividades de transporte rodoviário de produtos ou resíduos perigosos. Os documentos exigidos contemplam, além dos documentos legais da empresa, Certificado de Regularidade junto ao IBAMA, lista de veículos a serem licenciados e Plano de Ações Emergenciais (PAE).
\end{abstract}

Palavras-chave: Residuos de serviços sanitários; Administração hospitalar; Gestão estratégica em saúde; Auditorias ambientais.

\begin{abstract}
The objective of this work was to propose guidelines for sustainability managers who perform their duties within hospital units in Brazil. Assuming a qualitative analysis of the demand for documents and the set of norms common to the national scenario, it was possible to list the procedures in a guide for hospital units. These stablishments are responsible from the generation until the final destination of waste. However, as the transport and destination work is outsourced, this instrument may contribute to the verification and correction of possible non-conformities presented by the service providers. In the activities of collection and external transport of waste from health services, among the risks are the conditioning conditions for the transport, loading and unloading of trucks, risk of a road accident tipping of the truck, collision, etc. Thus, a series of conditions may be imposed by the environmental agency for the granting of an environmental or operating license for road transport activities of hazardous products or waste. The required documents include, in addition to the company's legal documents, a Certificate of Regularity with IBAMA, a list of vehicles to be licensed and an Emergency Action Plan (PAE).
\end{abstract}

Keywords: Waste from healthcare services; Hospital administration; Strategic healthcare management; Environmental audits.

\section{Resumen}

El objetivo de este trabajo fue proponer lineamientos para los gerentes de sustentabilidad que realizan sus funciones dentro de las unidades hospitalarias en Brasil. Asumiendo un análisis cualitativo de la demanda de documentos y el conjunto de normas comunes al escenario nacional, fue posible reunir los procedimientos en un checklist por unidades hospitalarias. Son los responsables desde la generación hasta el destino final de los residuos. No obstante, al estar subcontratados el trabajo de transporte y destino, este instrumento puede contribuir a la verificación y corrección de posibles no conformidades presentadas por las empresas subcontratadas. En las actividades de recogida y transporte 
externo de residuos de los servicios sanitarios, entre los riesgos se encuentran las condiciones de acondicionamiento para el transporte, carga y descarga de camiones, riesgo de accidente de tráfico - vuelco del camión, colisión, etc. Así, la agencia ambiental puede imponer una serie de condiciones para el otorgamiento de una licencia ambiental $u$ operativa para las actividades de transporte por carretera de productos o desechos peligrosos. Los documentos requeridos incluyen, además de los documentos legales de la empresa, un Certificado de Regularidad con IBAMA, una lista de vehículos a licenciar y un Plan de Acción de Emergencia (PAE).

Palabras clave: Residuos de servicios sanitarios; Administración hospitalaria; Gestión sanitaria estratégica; Auditorías ambientales.

\section{Introdução}

Atualmente, os contratos de produtos e serviços estão associados a critérios socioambientais indissociáveis da atividade produtiva. Algumas empresas passaram a aplicar formulários sobre questões ambientais a seus fornecedores ou a realizar auditorias para avaliar sua gestão ambiental. Isso implica em risco de suspensão de contratos, caso o fornecedor não atenda aos requisitos mínimos desejados. Nesse sentido, a incorporação da variável ambiental à gestão empresarial tornou-se não apenas um diferencial competitivo, mas uma questão de sobrevivência em longo prazo. Além da observância dos padrões de gestão, a população atendida pelos serviços passou a demandar produtos e processos produtivos com menor impacto no meio ambiente. As questões ambientais passaram a ganhar atenção crescente das organizações internacionais, dos governos, das empresas e da sociedade. Essa nova postura corporativa tem proporcionado a materialização e a aplicação de diversos mecanismos, objetivando não apenas detectar e mensurar possíveis problemas, como também o oferecimento de alternativas de soluções. Entre esses mecanismos, destacam-se as políticas de gestão de riscos relacionadas à auditoria ambiental, um instrumento que permite avaliar os sistemas de gestão ambiental, o grau de implementação e a eficiência dos planos/programas no controle da poluição ambiental, a conformidade legal e o controle ambiental de empreendimentos que exercem atividades potencialmente poluidoras.

\subsection{Sobre as auditorias}

A realização de uma auditoria é definida pela Associação Brasileira de Normas Técnicas (ABNT) NBR ISO 19011:2018 Versão Corrigida:2019 - Diretrizes como: "Processo sistemático, independente e documentado para obter evidência objetiva e avaliá-la objetivamente, para determinar a extensão na qual os critérios de auditoria são atendidos" (ABNT, 2018, p.1). A Norma ISO 19.011 oferece orientações para a Gestão de Programas de Auditorias, a condução de auditorias internas/externas de Sistemas de Gestão da Qualidade e Ambiental, bem como instruções para a avaliação da competência dos auditores.

As auditorias podem ser de primeira parte, quando conduzidas por uma empresa contando com seus próprios sistemas; de segunda parte, conduzidas por uma organização com que a empresa mantém uma relação comercial; ou de terceira parte, conduzidas por organismo independente, que pode ser credenciado, conforme Figura 1. 
Figura 1. Tipos de auditorias.

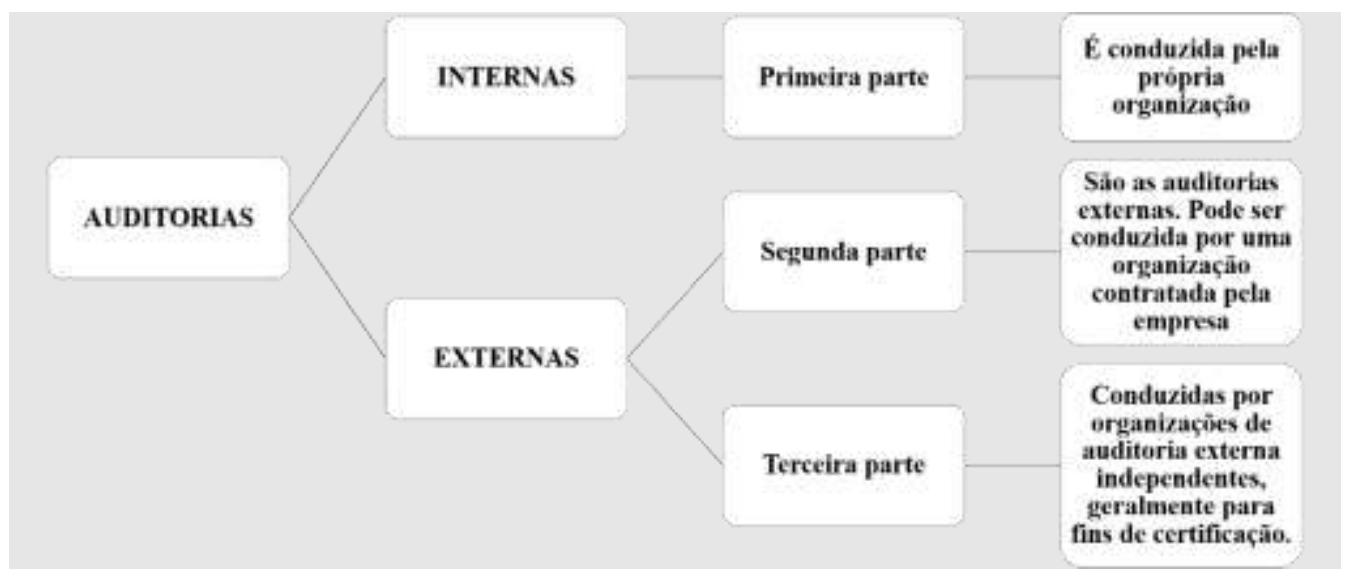

Fonte: Autores (2021).

A metodologia empregada em uma auditoria varia de acordo com a norma ou legislação, sob a qual os sistemas ou processos internos ou externos serão avaliados, como por exemplo, as auditorias de sistema de gestão ambiental tem como um dos fundamentos a norma ABNT NBR ISO 14001:2015 (ABNT, 2015). Já as auditorias de conformidade legal são realizadas conforme fundamentos da Resolução CONAMA no 306/2002, que define auditoria ambiental como: "um instrumento que permite avaliar o grau de implementação e a eficiência dos planos e programas no controle da poluição ambiental" (Brasil, 2002a, p.1) Com uma definição mais específica, o anexo I da mesma Resolução define ser auditoria ambiental o processo sistemático e documentado de verificação, executado para obter e avaliar, de forma objetiva, evidências que determinem se as atividades, eventos, sistemas de gestão e condições ambientais especificados ou as informações relacionadas a estes estão em conformidade com os critérios de auditoria estabelecidos nesta Resolução, e para comunicar os resultados desse processo.

As auditorias são realizadas conforme seu objetivo, que varia de acordo com sua classificação. Dentre as categorias mais aplicadas de auditorias destacam-se:

- Auditoria de conformidade legal: avalia a adequação da unidade auditada com a legislação e os regulamentos aplicáveis;

- Auditoria de desempenho ambiental: avalia a conformidade da unidade auditada com a legislação, os regulamentos aplicáveis e indicadores de desempenho ambiental setoriais aplicáveis à unidade;

- Auditoria de Sistema de Gestão Ambiental: avalia o cumprimento dos princípios estabelecidos no Sistema de Gestão Ambiental (SGA) da empresa e sua adequação e eficácia;

- Auditoria de certificação: avalia a conformidade da empresa com princípios estabelecidos nas normas pela qual a empresa esteja desejando se certificar;

- Auditoria de desativação: avalia os danos ao ecossistema e à população do entorno de alguma unidade empresarial em consequência de sua desativação (paralisação definitiva de suas atividades);

- Auditoria de responsabilidade: destinada a avaliar o passivo ambiental das empresas, ou seja, suas responsabilidades ambientais efetivas e potenciais;

- Auditoria de sítios: destinada a avaliar o estágio de contaminação de um determinado local;

- Auditoria pontual: destinada a otimizar a gestão dos recursos, a melhorar a eficiência do processo produtivo e, consequentemente, minimizar a geração de resíduos, o uso de energia ou de outros insumos. 


\subsection{Sobre as auditorias ambientais}

As auditorias ambientais foram iniciadas no final da década de 70, como obrigação imposta por agências regulamentadoras após acidentes graves decorrentes de explosões, vazamentos seguidos por contaminações em fábricas, refinarias, gasodutos, terminais portuários e outros. A partir da década de 1970 se tornou um instrumento autônomo de gestão ambiental, com objetivo de averiguar o cumprimento das leis ambientais que se tornavam cada vez mais rigorosas. As legislações ambientais passaram a cobrir cada vez mais as lacunas existentes no tocante ao controle dos impactos e se tornaram ainda mais restritivas à emissão de poluentes, à disposição de resíduos sólidos e líquidos, à emissão de ruídos e à ex ploração de recursos naturais. No Brasil, o marco regulatório na legislação ambiental ocorreu em 1981 com a criação da Lei federal ${ }^{\circ}$ 6.938, com o surgimento do Sistema Nacional de Meio Ambiente (SISNAMA), gerido pelo Conselho Nacional do Meio Ambiente (CONAMA). Essa lei instituiu ainda a Política Nacional do Meio Ambiente (PNMA) com seus objetivos e instrumentos (Brasil, 1981).

Em paralelo a uma série de exigências legais que foram surgindo, a existência de um mercado em crescente processo de mudança de paradigma. Mecanismos como selos verdes e normas, bem como a série ISO 14000, passaram a constituir atributos desejáveis. Isso se deu em relação à aceitação e compra de produtos e serviços, como também para a construção de uma imagem ambientalmente positiva junto à sociedade. A busca por produtos e processos produtivos de menor impacto no meio ambiente por parte da sociedade aumentou.

Frente a tamanha demanda, a auditoria ambiental é reconhecida em todo mundo como uma ferramenta básica de um sistema de gestão ambiental. É amplamente utilizada para descrever uma série de procedimentos utilizados por organizações para a avaliação dos impactos ambientais provocados por suas atividades.

Jones (1997, p.1) define auditoria ambiental como "o processo de verificação concebido para confirmar se as diretrizes de uma empresa em relação ao meio ambiente, e todos os procedimentos e regulamentos aplicáveis são cumpridos (...)".

Segundo a Agência de Proteção Ambiental dos Estados Unidos - EPA, a definição mais adequada para o termo auditoria ambiental é uma revisão sistemática, documentada periódica e objetiva por parte das entidades reguladas sobre as práticas e operações de suas instalações relativas aos requisitos ambientais.

Dado o potencial de riscos de acidentes de trabalho e impacto ambiental vinculadas às atividades de transporte de resíduos de serviços de saúde, em especial os classificados como resíduos biológicos, buscou-se com esta pesquisa, propor um instrumento para verificação de conformidades atinentes à coleta e transporte externos de resíduos biológicos em unidades de hospitalares. Foram considerados nesta análise o levantamento de dados a partir de instrumentos de pesquisa, consulta a trabalhos científicos e dados estatísticos abertos junto a órgão ambientais como IBGE, ANVISA, ABNT, CONAMA, Cadastro Nacional de Estabelecimentos de Saúde (CNES), Ministério da Saúde (MS) e Ministério da Previdência Social (MPS) sobre as atividades ligadas ao gerenciamento de resíduos de serviços de saúde.

\section{Metodologia}

A proposição dos checklists foi embasada nas principais referências legais e normativos técnicos ligados ao gerenciamento de resíduos de serviços de saúde e em auditorias, conforme apresentados nos Quadros 1, 2,3 e 4. A metodologia aplicada foi o estudo com gestores responsáveis pelo gerenciamento de resíduos de serviços de saúde atuantes em unidades hospitalares como grupo focal. São os principais aspectos que são recomendados serem observados nas inspeções visuais, nas entrevistas com os responsáveis pela execução das atividades e demais questões que subsidiem a na obtenção de evidências que permitam informações suficientes para fundamentar as constatações a respeito das não conformidades ou conformidades 
identificadas, e assim, avaliar a eficácia do sistema de gestão de um empreendimento cujas atividades estão relacionadas a coleta, transporte e tratamento de resíduos de serviços de saúde.

Ao longo da pesquisa, levou-se em consideração o caminho metodológico apontado por Fachin (2001), Rey (2005) e Gondim (2003). Considerou-se como método comparativo a definição de Fachin (2001, p.117):

... consiste em investigar coisas ou fatos e explicá-los segundo suas semelhanças e suas diferenças. Permite a análise de dados concretos e a dedução de semelhanças e divergências de elementos constantes, abstratos e gerais, propiciando investigações de caráter indireto.

Rey (2005) considera relevante nos diferentes momentos do processo da pesquisa a incorporação de outros aspectos que vão além dos processos matemáticos.

Quadro 1. Normas Técnicas da ABNT sobre Resíduos de Serviços de Saúde (RSS).

\begin{tabular}{|l|l|}
\hline Número & Descrição \\
\hline ABNT NBR 12807:2013 & Resíduos de serviços de saúde — Terminologia \\
\hline ABNT NBR 12808:2016 & Resíduos de serviços de saúde — Classificação \\
\hline ABNT NBR 12809:2013 & $\begin{array}{l}\text { Resíduos de serviços de saúde — Gerenciamento de resíduos de serviços de saúde } \\
\text { intraestabelecimento }\end{array}$ \\
\hline ABNT NBR 12810:2020 & Resíduos de serviços de saúde — Gerenciamento extraestabelecimento — Requisitos \\
\hline $\begin{array}{l}\text { ABNT NBR 13853-1:2018 Versão } \\
\text { Corrigida:2020 }\end{array}$ & $\begin{array}{l}\text { Recipientes para resíduos de serviços de saúde perfurantes ou cortantes - Requisitos } \\
\text { e métodos de ensaio } \\
\text { Parte 1: Recipientes descartáveis }\end{array}$ \\
\hline ABNT NBR 14652:2019 & $\begin{array}{l}\text { Implementos rodoviários — Coletor transportador de resíduos de serviços de saúde } \\
\text { - Requisitos de construção e inspeção }\end{array}$ \\
\hline
\end{tabular}

Fonte: Autores (2021).

O Quadro 1 reúne as normas técnicas da ABNT que devem ser consideradas pelos gestores dos setores de sustentabilidade das unidades de saúde. A adequação dos espaços e nomenclatura é uma etapa importante na gestão dos resíduos e proteção ao trabalhador. 
Quadro 2. Normas Técnicas da ABNT sobre resíduos sólidos.

\begin{tabular}{|c|c|}
\hline Número & Descrição \\
\hline ABNT NBR 7500:2020 & $\begin{array}{l}\text { Identificação para o transporte terrestre, manuseio, movimentação e armazenamento de } \\
\text { produtos }\end{array}$ \\
\hline ABNT NBR 7501:2020 & Transporte terrestre de produtos perigosos - Terminologia \\
\hline ABNT NBR 7503:2020 & $\begin{array}{l}\text { Transporte terrestre de produtos perigosos }- \text { Ficha de emergência }- \text { Requisitos } \\
\text { mínimos }\end{array}$ \\
\hline ABNT NBR 9191:2008 & Sacos plásticos para acondicionamento de lixo - Requisitos e métodos de ensaio \\
\hline ABNT NBR 9735:2020 & $\begin{array}{l}\text { Conjunto de equipamentos para emergências no transporte terrestre de produtos } \\
\text { perigosos }\end{array}$ \\
\hline ABNT NBR 10004:2004 & Resíduos sólidos - Classificação \\
\hline ABNT NBR 11175:1990 & Incineração de resíduos sólidos perigosos - Padrões de desempenho - Procedimento \\
\hline ABNT NBR 12235:1992 & Armazenamento de resíduos sólidos perigosos - Procedimento \\
\hline ABNT NBR 13221:2021 & Transporte terrestre de produtos perigosos - Resíduos \\
\hline ABNT NBR 13334:2017 & $\begin{array}{l}\text { Contentores metálicos } 0,8 \mathrm{~m} 3 \text { a } 1,6 \mathrm{~m} 3 \text { para coleta de resíduos sólidos por coletores- } \\
\text { compactadores de carregamento traseiro - Requisitos para fabricação e utilização }\end{array}$ \\
\hline $\begin{array}{l}\text { ABNT NBR 14064:2015 Versão } \\
\text { Corrigida:2015 }\end{array}$ & $\begin{array}{l}\text { Transporte rodoviário de produtos perigosos - Diretrizes do atendimento à } \\
\text { emergência }\end{array}$ \\
\hline ABNT NBR 14599:2020 & $\begin{array}{l}\text { Implementos rodoviários - Requisitos de segurança para coletores-compactadores de } \\
\text { resíduos sólidos }\end{array}$ \\
\hline ABNT NBR 14619:2018 & Transporte terrestre de produtos perigosos - Incompatibilidade química \\
\hline $\begin{array}{l}\text { ABNT NBR } 15480: 2018 \text { Versão } \\
\text { Corrigida:2018 }\end{array}$ & $\begin{array}{l}\text { Transporte rodoviário de produtos perigosos - Programa de gerenciamento de risco e } \\
\text { plano de ação de emergência }\end{array}$ \\
\hline ABNT NBR 16434:2015 & $\begin{array}{l}\text { Amostragem de resíduos sólidos, solos e sedimentos - Análise de compostos orgânicos } \\
\text { voláteis }(\mathrm{COV}) \text { - Procedimento }\end{array}$ \\
\hline ABNT NBR 16849:2020 & Resíduos sólidos urbanos para fins energéticos - Requisitos \\
\hline ABNT NBR 16725:2014 & $\begin{array}{l}\text { Resíduo químico — Informações sobre segurança, saúde e meio ambiente — Ficha } \\
\text { com dados de segurança de resíduos químicos (FDSR) e rotulagem }\end{array}$ \\
\hline ABNT NBR 16699-1:2018 & $\begin{array}{l}\text { Implementos rodoviários - Veículos coletores compactadores de resíduos sólidos e } \\
\text { seus dispositivos de elevação de contentores. Parte 1: Carregamento traseiro }\end{array}$ \\
\hline ABNT NBR 16699-2:2018 & $\begin{array}{l}\text { Implementos rodoviários - Veículos coletores compactadores de resíduos sólidos e } \\
\text { seus dispositivos de elevação de contentores. Parte 2: Carregamento lateral }\end{array}$ \\
\hline ABNT NBR 16701-1:2018 & $\begin{array}{l}\text { Implementos rodoviários - Contentores fixos para resíduos } \\
\text { Parte 1: Contentores com capacidade de até } 3200 \text { L com tampas para dispositivos de } \\
\text { elevação do tipo suporte giratório e suporte giratório duplo - Dimensões e projeto }\end{array}$ \\
\hline ABNT NBR 16701-2:2018 & $\begin{array}{l}\text { Implementos rodoviários - Contentores fixos para resíduos } \\
\text { Parte 2: Requisitos de funcionamento e métodos de ensaio }\end{array}$ \\
\hline ABNT NBR 16701-3:2018 & $\begin{array}{l}\text { Implementos Rodoviários - Contentores fixos para resíduos } \\
\text { Parte 3: Requisitos de segurança e higiene }\end{array}$ \\
\hline
\end{tabular}

Fonte: Autores (2021).

O Quadro 2 reúne as normas técnicas da ABNT que são referências para a gestão de resíduos sólidos, resultantes das mais diversas atividades (industrial, hospitalar, comercial etc.) 
Quadro 3. Normas Técnicas da ABNT sobre transporte terrestre de produtos perigosos.

\begin{tabular}{|l|l|}
\hline Número & Descrição \\
\hline ABNT NBR 7501:2020 & Transporte terrestre de produtos perigosos — Terminologia \\
\hline ABNT NBR 7503:2020 & $\begin{array}{l}\text { Transporte terrestre de produtos perigosos — Ficha de emergência - } \\
\text { Requisitos mínimos }\end{array}$ \\
\hline ABNT NBR 9735:2020 & $\begin{array}{l}\text { Conjunto de equipamentos para emergências no transporte terrestre de produtos } \\
\text { perigosos }\end{array}$ \\
\hline ABNT NBR 12982:2020 & $\begin{array}{l}\text { Transporte terrestre de produtos perigosos — Procedimentos para serviços de } \\
\text { limpeza ou de descontaminação }\end{array}$ \\
\hline ABNT NBR 13221:2021 & Transporte terrestre de produtos perigosos - Resíduos \\
\hline $\begin{array}{l}\text { ABNT NBR 14619:2018 } \\
\text { ABNT NBR 14619:2017 Emenda 1:2018 }\end{array}$ & Transporte terrestre de produtos perigosos - Incompatibilidade química \\
\hline $\begin{array}{l}\text { ABNT NBR 16173:2013 Ed 2 } \\
\text { ABNT NBR 16173:2013 Emenda 1:2013 } \\
\text { ABNT NBR 16173:2013 Errata 1:2013 }\end{array}$ & $\begin{array}{l}\text { Transporte terrestre de produtos perigosos - Carregamento, descarregamento } \\
\text { e transbordo a granel e embalados - Capacitação de colaboradores }\end{array}$ \\
\hline
\end{tabular}

Fonte: Autores (2021).

O Quadro 3 reúne as normas técnicas da ABNT relativas ao transporte terrestre de produtos perigosos em caso de emergências, incompatibilidade química etc. de forma que os riscos ao meio ambiente e à saúde pública possam ser gerenciados adequadamente.

Quadro 4. Legislações federais em vigor.

\begin{tabular}{|c|c|c|}
\hline Estado & Número & Descrição \\
\hline \multirow{7}{*}{ União } & $\begin{array}{l}\text { Resolução } \mathrm{n}^{\circ} 306, \text { de } 05 / 07 / 2002 \\
\text { (UN30949) }- \text { CONAMA - } \\
\text { CONSELHO NACIONAL DO MEIO } \\
\text { AMBIENTE }\end{array}$ & $\begin{array}{l}\text { Estabelece os requisitos mínimos e o termo de referência para a } \\
\text { realização de auditorias ambientais, objetivando avaliar os sistemas de } \\
\text { gestão e controle ambiental nos portos organizados e instalações } \\
\text { portuárias, plataformas e suas instalações de apoio e refinarias, tendo em } \\
\text { vista o cumprimento da legislação vigente e do licenciamento ambiental. }\end{array}$ \\
\hline & $\begin{array}{l}\text { Resolução } \mathrm{n}^{\circ} 381, \text { de } 14 / 12 / 2006 \\
\text { (UN39117) }-\quad \text { CONAMA - } \\
\text { CONSELHO NACIONAL DO MEIO } \\
\text { AMBIENTE }\end{array}$ & $\begin{array}{l}\text { Altera dispositivos da Resolução no } 306 \text {, de } 5 \text { de julho de } 2002 \text { e o } \\
\text { Anexo II, que dispõe sobre os requisitos mínimos para a realização de } \\
\text { auditoria ambiental. } \\
\text { Altera a Resolução } \mathrm{n}^{\circ} 306 \text {, de } 05 / 07 / 2002 \text { (art. } 4^{\circ} \text { e o Anexo II) }\end{array}$ \\
\hline & $\begin{array}{l}\text { PORTARIA N. }{ }^{\circ} 319 \text {, de } 15 \text { de agosto } \\
\text { de } 2003-\text { Ministério do Meio } \\
\text { Ambiente }\end{array}$ & $\begin{array}{l}\text { Estabelece os requisitos mínimos quanto ao credenciamento, registro, } \\
\text { certificação, qualificação, habilitação, experiência e treinamento } \\
\text { profissional de auditores ambientais para execução de auditorias } \\
\text { ambientais que especifica. }\end{array}$ \\
\hline & Portaria 192/2011 & $\begin{array}{l}\text { O Ministério do Meio Ambiente, alterou dispositivos da Portaria 319/03, } \\
\text { que estabeleceu os requisitos mínimos para o credenciamento, registro, } \\
\text { certificação, qualificação, habilitação, experiência e treinamento } \\
\text { profissional de auditores ambientais para execução de auditorias } \\
\text { ambientais especificadas no âmbito da Resolução CONAMA 306/02. }\end{array}$ \\
\hline & $\begin{array}{l}\text { RESOLUÇÃO DA DIRETORIA } \\
\text { COLEGIADA - RDC Nº 222, DE } 28 \\
\text { DE MARÇO DE } 2018\end{array}$ & $\begin{array}{l}\text { Regulamenta as Boas Práticas de Gerenciamento dos Resíduos de } \\
\text { Serviços de Saúde e dá outras providências. }\end{array}$ \\
\hline & $\begin{array}{l}\text { RESOLUÇÃO CONAMA n }{ }^{\circ} 358 \text {, de } \\
29 \text { de abril de } 2005 \\
\text { Publicada no DOU no } 84 \text {, de } 4 \text { de } \\
\text { maio de } 2005 \text {, Seção } 1 \text {, páginas } 63-65\end{array}$ & $\begin{array}{l}\text { Dispõe sobre o tratamento e a disposição final dos resíduos dos serviços } \\
\text { de saúde e dá outras providências. }\end{array}$ \\
\hline & $\begin{array}{l}\text { RESOLUÇÃO } \mathrm{N}^{\circ} 316 \text {, DE } 29 \text { DE } \\
\text { OUTUBRO DE } 2002\end{array}$ & $\begin{array}{l}\text { Dispõe sobre procedimentos e critérios para o funcionamento de sistemas } \\
\text { de tratamento térmico de resíduos }\end{array}$ \\
\hline
\end{tabular}

Fonte: Autores (2021). 
O Quadro 4 apresenta as principais resoluções e leis que se aplicam à Auditoria Ambiental no Brasil e que são importantes para o monitoramento e gestão do meio ambiente, bem como as resoluções da ANVISA e CONAMA sobre resíduos de serviços de saúde e tratamento por incineração.

\section{Resultados}

A pesquisa resultou na proposição dos checklists apresentados nos Quadros 5, 6, 7 e 8, elaborados para auxiliarem os profissionais que atuam junto a instituições de saúde com referências dos principais aspectos recomendados a serem observados nas auditorias junto aos prestadores de serviços ligados as atividades de coleta e transporte externo de resíduos biológicos, bem como em unidades de tratamento.

Nas atividades de coleta e transporte externo de resíduos de serviços de saúde observam-se entre os riscos as condições de acondicionamento para o transporte, carregamento e descarregamentos dos caminhões, risco de ocorrência de acidente rodoviário - tombamento do caminhão, abalroamento etc. Assim, uma série de condições poderão ser impostas pelo órgão ambiental para concessão da licença ambiental ou de operação referente às atividades de transporte rodoviário de produtos ou resíduos perigosos. São exemplos: a) controle das emissões atmosféricas dos veículos de transporte de produtos ou resíduos perigosos, conforme especificado nas Resoluções CONAMA $n^{\circ} 382 / 06, n^{\circ}$ 05/89, $n^{\circ}$ 03/90 e $n^{\circ}$ 08/90; b) controle das emissões de ruídos em consonância com os padrões definidos na Resolução CONAMA n ${ }^{\circ}$ 01/90; c) controle de emissão de fumaça preta por veículos automotores do ciclo diesel; d) realização dos serviços de manutenção mecânica, lubrificação, abastecimento e troca de óleo apenas por empresas licenciadas pelo órgão ambiental, mantendo os comprovantes à disposição da fiscalização; e) realização de lavagens de veículos da frota somente em áreas autorizadas para este fim; f) atendimento a ABNT NBR 13221:2021 que trata de transporte terrestre de produtos perigosos g) instalação de sistema de rastreabilidade online nos veículos transportadores de resíduos entre outros (ABNT, 2021).

Frente à complexidade do gerenciamento de resíduos de serviços de saúde é fundamental a conscientização dos profissionais quanto a responsabilidade socioambiental. Faz-se necessário que o estabelecimento de saúde disponha de mecanismos para o efetivo controle e a eficácia do processo de gerenciamento de resíduos de serviços de saúde em todas as fases, desde a coleta interna, acondicionamento, armazenamento interno e externo, coleta, transporte, tratamento até a disposição final. Nesse contexto, a auditoria ambiental, segundo Machado (2001, p.278) é "um procedimento de exame e avaliação periódica ou ocasional do comportamento de uma empresa em relação ao meio ambiente". 
Quadro 5. Lista de verificação para auditorias ambientais junto a empresas de coleta e transporte externos de resíduos biológicos (Grupo A)

\begin{tabular}{|c|c|c|c|}
\hline Coleta externa RSS biológicos & Conforme & $\begin{array}{c}\text { Não- } \\
\text { conforme }\end{array}$ & $\begin{array}{l}\text { Não se } \\
\text { aplica }\end{array}$ \\
\hline $\begin{array}{l}\text { Uso adequado por parte dos funcionários de todos os EPIs necessários } \\
\text { ao correto manejo dos resíduos biológicos? }\end{array}$ & $\square$ & $\square$ & $\square$ \\
\hline $\begin{array}{l}\text { Uso de veículos apropriados para o transporte de RSS biológicos? Nota: } \\
\text { Segundo a RDC } n^{\circ} 222 / 2018 / \text { ANVISA, a coleta externa de RSS com o } \\
\text { uso de veículo compactador, equipado com dispositivos hidráulicos } \\
\text { para basculamento dos resíduos é permitida em estabelecimentos de } \\
\text { saúde somente para os resíduos comuns, equiparados aos domiciliares. } \\
\text { Veículos baú com carroceria fixa retangular e veículos leves, como } \\
\text { furgões e motonetas são os recomendados pelos órgãos competentes, } \\
\text { pois os sacos devem ser mantidos íntegros. }\end{array}$ & $\square$ & $\square$ & $\square$ \\
\hline $\begin{array}{l}\text { Veículos utilizados na coleta externa são os que constam relacionados } \\
\text { no Atestado de Conformidade de Frota, liberados pelo Certificado de } \\
\text { Credenciamento pelo órgão competente? }\end{array}$ & $\square$ & $\square$ & $\square$ \\
\hline $\begin{array}{l}\text { Veículos devidamente identificados com as seguintes informações: a) } \\
\text { logomarca e nome da empresa; b) Telefone de contato; c) Tipificação } \\
\text { do resíduo coletado. d) sinalização padronizada de riscos das cargas } \\
\text { transportadas, com o estabelecimento de simbologias, definições de } \\
\text { classes e subclasses e outros aspectos de segurança, conforme norma } \\
\text { ABNT NBR 7500:2020. }\end{array}$ & $\square$ & $\square$ & $\square$ \\
\hline Veículos em bom estado de conservação? & $\square$ & $\square$ & $\square$ \\
\hline $\begin{array}{l}\text { Equipamentos e materiais disponíveis nos veículos para os casos de } \\
\text { emergências, adequado ao tipo de produto transportado e devidamente } \\
\text { localizado, conforme artigo } 8^{\circ} \text { da Resolução n }{ }^{\circ} 5.848 / 19 / \text { ANTT? }\end{array}$ & $\square$ & $\square$ & $\square$ \\
\hline $\begin{array}{l}\text { Veículos com instalação de rastreadores permitindo controle e } \\
\text { fiscalização remota? }\end{array}$ & $\square$ & $\square$ & $\square$ \\
\hline $\begin{array}{l}\text { Terceirizada possui contrato de rastreamento com empresa } \\
\text { especializada no ramo? Se sim, qual? }\end{array}$ & $\square$ & $\square$ & $\square$ \\
\hline $\begin{array}{l}\text { Veículos utilizados possuem um conjunto mínimo de EPIs para seus } \\
\text { condutores e auxiliares, conforme o tipo de produto transportado, em } \\
\text { caso de emergências, conforme artigo } 9^{\circ} \text { da Resolução }{ }^{\circ} \\
\text { 5.848/19/ANTT? }\end{array}$ & $\square$ & $\square$ & $\square$ \\
\hline Transporte externo RSS biológicos & Conforme & $\begin{array}{c}\text { Não- } \\
\text { conforme }\end{array}$ & $\begin{array}{l}\text { Não se } \\
\text { aplica }\end{array}$ \\
\hline $\begin{array}{l}\text { Condutores dos veículos estão qualificados no curso Movimentação e } \\
\text { Operação de Produtos Perigosos (MOPP), conforme artigo } 20 \text { da } \\
\text { Resolução ANTT no } 5.848 / 2019 \text {, em que estabelece a obrigatoriedade? } \\
\text { Nota: Resolução CONTRAN no } 205 / 2006 \text {, art. } 2^{\circ} \text { e estabelece: sempre } \\
\text { que for obrigatória a aprovação em curso especializado, o condutor } \\
\text { deverá portar sua comprovação até que essa informação seja registrada } \\
\text { no RENACH e incluída, em campo específico da CNH, nos termos do } \S \\
4^{\circ} \text { do art. } 33 \text { da Resolução do CONTRAN no } 168 / 2005 \text {. }\end{array}$ & $\square$ & $\square$ & $\square$ \\
\hline $\begin{array}{l}\text { Sacos de lixo biológico sendo transportados nos veículos devidamente } \\
\text { confinados em recipientes estanques de material rígido e resistente? }\end{array}$ & $\square$ & $\square$ & $\square$ \\
\hline $\begin{array}{l}\text { Há comprovação de que efetuam, diariamente, a limpeza, } \\
\text { desodorização e desinfecção dos veículos utilizados na remoção de RSS } \\
\text { biológicos? }\end{array}$ & $\square$ & $\square$ & $\square$ \\
\hline $\begin{array}{l}\text { A limpeza dos veículos utilizados no transporte de resíduos biológicos é } \\
\text { feita dentro ou fora da unidade? Nota: independentemente de ser dentro } \\
\text { ou fora, verifique sobre o tipo de tratamento e de destinação do } \\
\text { efluente. }\end{array}$ & $\square$ & $\square$ & $\square$ \\
\hline
\end{tabular}

Fonte: Autores (2021).

O Quadro 5 reúne as principais recomendações, embasadas nas legislações vigentes, a serem observadas em auditorias ambientais externas junto a empresas de coleta e transporte externos de resíduos biológicos. 
Quadro 6. Lista de verificação para auditorias ambientais junto a empresas de tratamento externo de resíduos biológicos Método por autoclavação (Grupo A).

\begin{tabular}{|c|c|c|c|}
\hline Gestão de resíduos & Conforme & $\begin{array}{c}\text { Não- } \\
\text { conforme }\end{array}$ & $\begin{array}{l}\text { Não se } \\
\text { aplica }\end{array}$ \\
\hline $\begin{array}{l}\text { Controle de peso dos caminhões (entrada e saída)? Há comprovação } \\
\text { por meio de registros? }\end{array}$ & $\square$ & $\square$ & $\square$ \\
\hline $\begin{array}{l}\text { O armazenamento temporário de resíduos é realizado em área coberta, } \\
\text { impermeabilizada e com segregação por tipo de resíduos? Local } \\
\text { fechado com controle de } \\
\text { acesso, dotado de sistema de contenção, construído e operado conforme } \\
\text { norma ABNT NBR } 12.235 \text { ? }\end{array}$ & $\square$ & $\square$ & $\square$ \\
\hline Identificação adequada dos recipientes de resíduos? & $\square$ & $\square$ & $\square$ \\
\hline As condições de manipulação dos resíduos estão adequadas? & $\square$ & $\square$ & $\square$ \\
\hline Unidade possui Plano para o gerenciamento de resíduos sólidos? & $\square$ & $\square$ & $\square$ \\
\hline $\begin{array}{l}\text { Possui área exclusiva para higienização dos recipientes utilizados na } \\
\text { coleta externa dos resíduos? }\end{array}$ & $\square$ & $\square$ & $\square$ \\
\hline $\begin{array}{l}\text { Regularidade na emissão de todos os Manifestos de Transportes de } \\
\text { Resíduos (MTR), de forma eletrônica, por meio do sistema SINIR? }\end{array}$ & $\square$ & $\square$ & $\square$ \\
\hline Processo de tratamento por autoclavação & Conforme & $\begin{array}{c}\text { Não- } \\
\text { conforme }\end{array}$ & $\begin{array}{l}\text { Não se } \\
\text { aplica }\end{array}$ \\
\hline $\begin{array}{l}\text { Capacidade de autoclavagem compatível com os RSS coletados? Nota: } \\
\text { questionar capacidade de processamento t/dia }\end{array}$ & $\square$ & $\square$ & $\square$ \\
\hline $\begin{array}{l}\text { Resíduos são inseridos na Autoclave de forma mecanizada? Nota: } \\
\text { geralmente por uma escotilha } \\
\text { dianteira semimecanizada, por onde ingressa o comboio de carros tipo } \\
\text { vagonetes }\end{array}$ & $\square$ & $\square$ & $\square$ \\
\hline $\begin{array}{l}\text { O tempo de tratamento térmico na autoclave está adequado? Nota: } \\
\text { geralmente a uma temperatura constante de } 150{ }^{\circ} \mathrm{C} \text { por um período de } \\
30 \text { minutos. }\end{array}$ & $\square$ & $\square$ & $\square$ \\
\hline $\begin{array}{l}\text { Autoclave dotada de válvulas de segurança termo resistentes para } \\
\text { controle de temperatura, vacuostato para controle de vácuo e pressão, } \\
\text { rampa e elevador pneumático para os carros de aço inoxidável e } \\
\text { compressor? }\end{array}$ & $\square$ & $\square$ & $\square$ \\
\hline $\begin{array}{l}\text { Disponibilidade de container frigorífico (câmara fria) para os casos de } \\
\text { problemas técnicos na operação e/ou emergências? }\end{array}$ & $\square$ & $\square$ & $\square$ \\
\hline $\begin{array}{l}\text { Capacidade de estocagem da câmara fria compatível com a demanda } \\
\text { em caso de problemas técnicos na autoclave? }\end{array}$ & $\square$ & $\square$ & $\square$ \\
\hline Caldeira a gás (GLP) localizada fora da área de tratamento? & $\square$ & $\square$ & $\square$ \\
\hline $\begin{array}{l}\text { Os resíduos autoclavados são estocados posteriormente de forma } \\
\text { adequada (tambores, caçambas estacionarias etc.) }\end{array}$ & $\square$ & $\square$ & $\square$ \\
\hline $\begin{array}{l}\text { Área de descarga de resíduos termicamente tratados é coberta, fechada } \\
\text { nas laterais e dotada de piso impermeável circundado por canaletas de } \\
\text { drenagem? }\end{array}$ & $\square$ & $\square$ & $\square$ \\
\hline $\begin{array}{l}\text { As emissões atmosféricas produzidas pelo Autoclave correspondem aos } \\
\text { vapores d'água expelidos pelo sistema. As emissões atmosféricas estão } \\
\text { sendo geridas adequadamente? }\end{array}$ & $\square$ & $\square$ & $\square$ \\
\hline $\begin{array}{l}\text { Os ruídos gerados pelos equipamentos (Caldeira, motores e } \\
\text { ventiladores centrífugos) estão dentro dos níveis aceitáveis? }\end{array}$ & $\square$ & $\square$ & $\square$ \\
\hline Gestão da água & Conforme & $\begin{array}{c}\text { Não- } \\
\text { conforme }\end{array}$ & $\begin{array}{l}\text { Não se } \\
\text { aplica }\end{array}$ \\
\hline Possui poço artesiano? & $\square$ & $\square$ & $\square$ \\
\hline No caso de poço artesiano, outorga em dia? & $\square$ & $\square$ & $\square$ \\
\hline Gestão de efluentes & Conforme & $\begin{array}{l}\text { Não- } \\
\text { conforme }\end{array}$ & $\begin{array}{l}\text { Não se } \\
\text { aplica }\end{array}$ \\
\hline $\begin{array}{l}\text { Os efluentes gerados são direcionados por meio de canaletas de } \\
\text { drenagem existentes no piso para a Estação de Tratamento de } \\
\text { Efluentes? (efluentes sanitários, a água do processo de autoclavagem } \\
\text { (condensado), água de lavagem dos recipientes de armazenagem de } \\
\text { resíduos, água de lavagem de piso e equipamentos etc.) }\end{array}$ & $\square$ & $\square$ & $\square$ \\
\hline $\begin{array}{l}\text { Os efluentes provenientes da lavagem e desinfecção são encaminhados } \\
\text { para sistema de tratamento dentro dos padrões estabelecidos pelo órgão } \\
\text { ambiental? }\end{array}$ & $\square$ & $\square$ & $\square$ \\
\hline $\begin{array}{l}\text { Há comprovação da eficiência da ETE? Nota: tratamento dos efluentes } \\
\text { através dos processos de decantação, tratamento químico etc. }\end{array}$ & $\square$ & $\square$ & $\square$ \\
\hline
\end{tabular}




\begin{tabular}{|c|c|c|c|}
\hline Gestão ambiental & Conforme & $\begin{array}{c}\text { Não- } \\
\text { conforme }\end{array}$ & $\begin{array}{l}\text { Não se } \\
\text { aplica }\end{array}$ \\
\hline $\begin{array}{l}\text { Identificação do responsável técnico pela gestão ambiental na unidade } \\
\text { de tratamento? } \\
\text { Nota: Anotação de Responsabilidade Técnica (ART) no respectivo } \\
\text { Conselho de Classe (Conselho Regional de Engenharia e Agronomia - } \\
\text { CREA, Conselho Regional de Química - CRQ ou Conselho Regional } \\
\text { de Biologia - CRBio) }\end{array}$ & $\square$ & $\square$ & $\square$ \\
\hline Possui Sistema de Gestão Ambiental? Objetivos e Metas Ambientais? & $\square$ & $\square$ & $\square$ \\
\hline Possui Política de Qualidade, Saúde e Segurança e Meio Ambiente? & $\square$ & $\square$ & $\square$ \\
\hline $\begin{array}{l}\text { Possui implementados Procedimentos Operacionais de Controle } \\
\text { Ambiental? Avalie quais procedimentos possui para os aspectos } \\
\text { ambientais? }\end{array}$ & $\square$ & $\square$ & $\square$ \\
\hline $\begin{array}{l}\text { Possui Programas de treinamento e capacitação técnica dos } \\
\text { responsáveis pela operação e manutenção dos sistemas, rotinas, } \\
\text { instalações e equipamentos de proteção ao meio ambiente ou que } \\
\text { possuem o potencial de causar danos ambientais? }\end{array}$ & $\square$ & $\square$ & $\square$ \\
\hline $\begin{array}{l}\text { Mantem atualizado o Plano de Ação de Emergências (PAE) } \\
\text { contemplando o procedimento de comunicação de acidentes } \\
\text { ambientais? }\end{array}$ & $\square$ & $\square$ & $\square$ \\
\hline $\begin{array}{l}\text { Registros de manutenção dos principais equipamentos que causam risco } \\
\text { às atividades, bem como os dos equipamentos de combates às } \\
\text { emergências? }\end{array}$ & $\square$ & $\square$ & $\square$ \\
\hline $\begin{array}{l}\text { Há registro de ocorrência de acidentes que tenham gerado algum } \\
\text { impacto ambiental no período contemplado pela auditoria? }\end{array}$ & $\square$ & $\square$ & $\square$ \\
\hline Possui Plano de Contingência? & $\square$ & $\square$ & $\square$ \\
\hline Saúde e segurança do trabalho & Conforme & $\begin{array}{c}\text { Não- } \\
\text { conforme }\end{array}$ & $\begin{array}{l}\text { Não se } \\
\text { aplica }\end{array}$ \\
\hline $\begin{array}{l}\text { Regularidade quanto ao Auto de Vistoria do Corpo de Bombeiros } \\
\text { aprovando o projeto e as instalações de combate a incêndio e pânico? }\end{array}$ & $\square$ & $\square$ & $\square$ \\
\hline $\begin{array}{l}\text { Os controles e equipamentos do sistema de emergência são } \\
\text { inspecionados periodicamente pelos brigadistas? }\end{array}$ & $\square$ & $\square$ & $\square$ \\
\hline Simulados de emergência realizados periodicamente? & $\square$ & $\square$ & $\square$ \\
\hline $\begin{array}{l}\text { Registros de treinamentos periódicos do pessoal incumbido da operação } \\
\text { normal e o de ação em emergência, mantendo o registro dos } \\
\text { treinamentos (pessoal treinado, instrutor e conteúdo programático)? }\end{array}$ & $\square$ & $\square$ & $\square$ \\
\hline $\begin{array}{l}\text { Programa de Prevenção de Riscos Ambientais - PPRA disponível e } \\
\text { atualizado? }\end{array}$ & $\square$ & $\square$ & $\square$ \\
\hline $\begin{array}{l}\text { Programa de Controle Médico de Saúde Ocupacional - PCMSO } \\
\text { disponível e atualizado? }\end{array}$ & $\square$ & $\square$ & $\square$ \\
\hline $\begin{array}{l}\text { Lavatório exclusivo para higiene das mãos provido de água corrente, } \\
\text { sabonete líquido, toalha descartável e lixeira provida de sistema de } \\
\text { abertura sem contato manual disponíveis nas instalações da unidade? }\end{array}$ & $\square$ & $\square$ & $\square$ \\
\hline $\begin{array}{l}\text { Comprovação do Programa de imunização estabelecidos no PCMSO } \\
\text { (tétano, hepatite B etc.) }\end{array}$ & $\square$ & $\square$ & $\square$ \\
\hline $\begin{array}{l}\text { Destinação dada aos EPIs usados e contaminados feito de forma } \\
\text { adequada? }\end{array}$ & $\square$ & $\square$ & $\square$ \\
\hline
\end{tabular}

Fonte: Autores (2021).

O Quadro 6 contempla os principais aspectos a serem verificados pelos gestores nas auditorias ambientais ou visitas técnicas junto a unidades de tratamento de resíduos de serviços de saúde, bem como aspectos relevantes acerca do sistema de gestão ambiental e de segurança do trabalhador. 
Quadro 7. Lista de verificação para auditorias ambientais junto a empresas de tratamento externo de resíduos biológicos Incineração (Grupo A).

\begin{tabular}{|c|c|c|c|}
\hline Gestão de resíduos & Conforme & $\begin{array}{c}\text { Não- } \\
\text { conforme }\end{array}$ & $\begin{array}{l}\text { Não se } \\
\text { aplica }\end{array}$ \\
\hline Controle de peso dos caminhões (entrada e saída)? Há registros? & $\square$ & $\square$ & $\square$ \\
\hline $\begin{array}{l}\text { O armazenamento temporário de resíduos é realizado em área coberta, } \\
\text { impermeabilizada e com segregação por tipo de resíduos? Local } \\
\text { fechado com controle de } \\
\text { acesso, dotado de sistema de contenção, construído e operado conforme } \\
\text { norma ABNT NBR 12.235? }\end{array}$ & $\square$ & $\square$ & $\square$ \\
\hline Identificação adequada dos recipientes de resíduos? & $\square$ & $\square$ & $\square$ \\
\hline As condições de manipulação dos resíduos estão adequadas? & $\square$ & $\square$ & $\square$ \\
\hline plano para o gerenciamento de resíduos sólidos & $\square$ & $\square$ & $\square$ \\
\hline $\begin{array}{l}\text { Possui área exclusiva para higienização dos recipientes utilizados na } \\
\text { coleta externa dos resíduos? }\end{array}$ & $\square$ & $\square$ & $\square$ \\
\hline $\begin{array}{l}\text { Regularidade na emissão de todos os Manifestos de Transportes de } \\
\text { Resíduos (MTR), de forma eletrônica, por meio do sistema SINIR? }\end{array}$ & $\square$ & $\square$ & $\square$ \\
\hline Processo de tratamento por incineração & Conforme & $\begin{array}{c}\text { Não- } \\
\text { conforme }\end{array}$ & $\begin{array}{l}\text { Não se } \\
\text { aplica }\end{array}$ \\
\hline Capacidade de processamento $\mathrm{Kg} / \mathrm{h}$ compatível com a demanda? & $\square$ & $\square$ & $\square$ \\
\hline $\begin{array}{l}\text { A inserção dos resíduos para dentro da câmara primária de combustão é } \\
\text { feito adequadamente? } \\
\text { Nota: a câmara do módulo de alimentação é composta de duas } \\
\text { comportas de fechamento sequencial, evitando-se, desta forma, a fuga } \\
\text { dos gases da Câmara Primária para o ambiente de trabalho, protegendo } \\
\text { a saúde do operador e o meio ambiente? }\end{array}$ & $\square$ & $\square$ & $\square$ \\
\hline $\begin{array}{l}\text { O equipamento opera na faixa de temperatura mínima de } 800^{\circ} \mathrm{C} \text {, uma } \\
\text { exigência da Resolução CONAMA n }{ }^{\circ} .316 / 2002 \text {, em seu artigo } 2^{\circ} \text {, } \\
\text { inciso III? }\end{array}$ & $\square$ & $\square$ & $\square$ \\
\hline $\begin{array}{l}\text { Possui sistemas de resfriamento através de aspersores de água, } \\
\text { acionados sempre que houver necessidade de controle da temperatura } \\
\text { máxima? }\end{array}$ & $\square$ & $\square$ & $\square$ \\
\hline $\begin{array}{l}\text { O incinerador é dotado de monitoramento eletrônico de temperaturas e } \\
\text { pressão e de um sistema de intertravamento, conforme Resolução } \\
\text { CONAMA n }{ }^{\circ} \text {. } \\
\text { 316/2002, em seu Artigo 36, Inciso-IV. }\end{array}$ & $\square$ & $\square$ & $\square$ \\
\hline $\begin{array}{l}\text { Equipamento possui sistema Lavador de Gases, cuja função é precipitar } \\
\text { o macro pó, lavar o micro pó e coloides e neutralizar os gases ácidos? }\end{array}$ & $\square$ & $\square$ & $\square$ \\
\hline $\begin{array}{l}\text { O monitoramento dos gases é feito por um sistema eletrônico on-line, } \\
\text { conforme, Resolução CONAMA no }{ }^{\circ} .316 / 2002 \text { ? Nota: questione sobre o } \\
\text { monitoramento contínuo dos gases NOx, SOx, compostos clorados, } \\
\text { compostos fluorados, dioxinas e furanos }\end{array}$ & $\square$ & $\square$ & $\square$ \\
\hline Apresentado Plano de Queima? & $\square$ & $\square$ & $\square$ \\
\hline $\begin{array}{l}\text { Unidade realiza Teste de Queima, conforme a Resolução CONAMA n }{ }^{\circ} \text {. } \\
316 / 2002 \text { requerido pela } \\
\text { citada legislação em seus Artigos } n^{\circ} .33,34,35 \text { e } 36\end{array}$ & $\square$ & $\square$ & $\square$ \\
\hline $\begin{array}{l}\text { As cinzas, escórias e resíduos de fundo do Lavador de Gases geradas no } \\
\text { processo de incineração são devidamente acondicionadas, identificadas } \\
\text { e envidas para resíduos Classe I - Perigoso, conforme Resolução } \\
\text { CONAMA n }{ }^{\circ} .316 / 2002 \text { em seu Art. } 43, \S 1^{\circ} \text { ? }\end{array}$ & $\square$ & $\square$ & $\square$ \\
\hline $\begin{array}{l}\text { Os efluentes líquidos presentes no processo de incineração (água de } \\
\text { resfriamento e lavagem } \\
\text { de gases) são recirculados no próprio sistema? }\end{array}$ & $\square$ & $\square$ & $\square$ \\
\hline $\begin{array}{l}\text { O incinerador dispõe de sensores de monitoramento contínuo de } \mathrm{CO} \text { e } \\
\mathrm{O} 2 \text { ? }\end{array}$ & $\square$ & $\square$ & $\square$ \\
\hline $\begin{array}{l}\text { Os ruídos gerados em razão do funcionamento do Incinerador e seus } \\
\text { assessórios (motores e ventiladores centrífugos, lavador de Gás) são } \\
\text { monitorados? Há comprovação? }\end{array}$ & $\square$ & $\square$ & $\square$ \\
\hline Plano de emergência e contingência apresentados? & $\square$ & $\square$ & $\square$ \\
\hline $\begin{array}{l}\text { Realizado “Análise de Risco", conforme Resolução CONAMA nº. } \\
316 / 2002 \text {, art. } 26 \text { ? }\end{array}$ & $\square$ & $\square$ & $\square$ \\
\hline Gestão da água & Conforme & $\begin{array}{l}\text { Não- } \\
\text { conforme }\end{array}$ & $\begin{array}{l}\text { Não se } \\
\text { aplica }\end{array}$ \\
\hline Possui poço artesiano? & $\square$ & $\square$ & $\square$ \\
\hline
\end{tabular}




\begin{tabular}{|c|c|c|c|}
\hline No caso de poço artesiano, outorga está em dia? & $\square$ & $\square$ & $\square$ \\
\hline Gestão de efluentes & Conforme & $\begin{array}{c}\text { Não- } \\
\text { conforme }\end{array}$ & $\begin{array}{l}\text { Não se } \\
\text { aplica }\end{array}$ \\
\hline $\begin{array}{l}\text { Os efluentes gerados são direcionados por meio de canaletas de } \\
\text { drenagem existentes no piso para a Estação de Tratamento de } \\
\text { Efluentes? (efluentes sanitários, a água do processo de autoclavagem } \\
\text { (condensado), água de lavagem dos recipientes de armazenagem de } \\
\text { resíduos, água de lavagem de piso e equipamentos etc.) }\end{array}$ & $\square$ & $\square$ & $\square$ \\
\hline $\begin{array}{l}\text { Os efluentes provenientes da lavagem e desinfecção são encaminhados } \\
\text { para sistema de tratamento dentro dos padrões estabelecidos pelo órgão } \\
\text { ambiental? }\end{array}$ & $\square$ & $\square$ & $\square$ \\
\hline $\begin{array}{l}\text { Há comprovação da eficiência da ETE? Nota: tratamento dos efluentes } \\
\text { através dos processos de decantação, tratamento químico etc. }\end{array}$ & $\square$ & $\square$ & $\square$ \\
\hline Gestão ambiental & Conforme & $\begin{array}{c}\text { Não- } \\
\text { conforme }\end{array}$ & $\begin{array}{l}\text { Não se } \\
\text { aplica }\end{array}$ \\
\hline $\begin{array}{l}\text { Identificação do responsável técnico pela gestão ambiental na unidade } \\
\text { de tratamento? Anotação de Responsabilidade Técnica (ART) no } \\
\text { respectivo Conselho de Classe (Conselho Regional de Engenharia e } \\
\text { Agronomia - CREA, Conselho Regional de Química - CRQ ou } \\
\text { Conselho Regional de Biologia - CRBio) }\end{array}$ & $\square$ & $\square$ & $\square$ \\
\hline Possui Sistema de Gestão Ambiental? Objetivos e Metas Ambientais? & $\square$ & $\square$ & $\square$ \\
\hline Possui Política de Qualidade, Saúde e Segurança e Meio Ambiente? & $\square$ & $\square$ & $\square$ \\
\hline $\begin{array}{l}\text { Possui implementados Procedimentos Operacionais de Controle } \\
\text { Ambiental? Avalie quais procedimentos possui para os aspectos } \\
\text { ambientais? }\end{array}$ & $\square$ & $\square$ & $\square$ \\
\hline $\begin{array}{l}\text { Possui Programas de treinamento e capacitação técnica dos } \\
\text { responsáveis pela operação e manutenção dos sistemas, rotinas, } \\
\text { instalações e equipamentos de proteção ao meio ambiente ou que } \\
\text { possuem o potencial de causar danos ambientais? }\end{array}$ & $\square$ & $\square$ & $\square$ \\
\hline $\begin{array}{l}\text { Mantem atualizado o Plano de Ação de Emergências (PAE) } \\
\text { contemplado o procedimento de comunicação de acidentes ambientais? }\end{array}$ & $\square$ & $\square$ & $\square$ \\
\hline $\begin{array}{l}\text { Registros de manutenção dos principais equipamentos que causam risco } \\
\text { às atividades, bem como os dos equipamentos de combates às } \\
\text { emergências? }\end{array}$ & $\square$ & $\square$ & $\square$ \\
\hline $\begin{array}{l}\text { Há registro de ocorrência de acidentes que tenham gerado algum } \\
\text { impacto ambiental no período contemplado pela auditoria? }\end{array}$ & $\square$ & $\square$ & $\square$ \\
\hline Possui Plano de Contingência? & $\square$ & $\square$ & $\square$ \\
\hline Saúde e segurança do trabalho & Conforme & $\begin{array}{c}\text { Não- } \\
\text { conforme }\end{array}$ & $\begin{array}{l}\text { Não se } \\
\text { aplica }\end{array}$ \\
\hline $\begin{array}{l}\text { Regularidade quanto ao Auto de Vistoria do Corpo de Bombeiros } \\
\text { aprovando o projeto e as instalações de combate a incêndio e pânico? }\end{array}$ & $\square$ & $\square$ & $\square$ \\
\hline $\begin{array}{l}\text { Os controles e equipamentos do sistema de emergência são } \\
\text { inspecionados periodicamente pelos brigadistas? }\end{array}$ & $\square$ & $\square$ & $\square$ \\
\hline Simulados de emergência realizados periodicamente? & $\square$ & $\square$ & $\square$ \\
\hline $\begin{array}{l}\text { Registros de treinamentos periódicos do pessoal incumbido da operação } \\
\text { normal e o de ação em emergência, mantendo o registro dos } \\
\text { treinamentos (pessoal treinado, instrutor e conteúdo programático)? }\end{array}$ & $\square$ & $\square$ & $\square$ \\
\hline $\begin{array}{l}\text { Programa de Prevenção de Riscos Ambientais - PPRA disponível e } \\
\text { atualizado? }\end{array}$ & $\square$ & $\square$ & $\square$ \\
\hline $\begin{array}{l}\text { Programa de Controle Médico de Saúde Ocupacional - PCMSO } \\
\text { disponível e atualizado? }\end{array}$ & $\square$ & $\square$ & $\square$ \\
\hline $\begin{array}{l}\text { Lavatório exclusivo para higiene das mãos provido de água corrente, } \\
\text { sabonete líquido, toalha descartável e lixeira provida de sistema de } \\
\text { abertura sem contato manual disponíveis nas instalações da unidade? }\end{array}$ & $\square$ & $\square$ & $\square$ \\
\hline $\begin{array}{l}\text { Comprovação do Programa de imunização estabelecidos no PCMSO } \\
\text { (tétano, hepatite B etc.) }\end{array}$ & $\square$ & $\square$ & $\square$ \\
\hline $\begin{array}{l}\text { Destinação dada aos EPIs usados e contaminados feito de forma } \\
\text { adequada? }\end{array}$ & $\square$ & $\square$ & $\square$ \\
\hline
\end{tabular}

Fonte: Autores (2021). 
Quadro 8. Lista de Documentos Necessários para Empresas de Transporte Rodoviário de Resíduos Perigosos Documentações de porte obrigatório no transporte de cargas perigosas.

\begin{tabular}{|c|c|c|}
\hline Item & Descrição & Fundamento Técnico/Legal \\
\hline 1 & $\begin{array}{l}\text { Licença de funcionamento/operação ambiental (avaliar } \\
\text { condicionantes) }\end{array}$ & Licença de funcionamento/operação ambiental; \\
\hline 2 & Alvará de localização e funcionamento & $\begin{array}{l}\text { Alvará de localização e funcionamento, emitido pelo órgão } \\
\text { municipal }\end{array}$ \\
\hline 3 & Auto de Vistoria do Corpo de Bombeiros (AVCB) & Atestado de Regularidade do Corpo de Bombeiros \\
\hline 4 & $\begin{array}{l}\text { Certificado de Registro e Licenciamento do Veículo } \\
\text { (CRLV) }\end{array}$ & $\begin{array}{l}\text { Código de Trânsito Brasileiro - CTB e Lei N 9.503, de 23/09/97, } \\
\text { art. } 120 \text {, art. } 133 \text {. }\end{array}$ \\
\hline 5 & $\begin{array}{l}\text { Certificados de Inspeção para o Transporte de Produtos } \\
\text { Perigosos (CIPP) }\end{array}$ & \\
\hline 6 & $\begin{array}{l}\text { Certificados de Inspeção Veicular (CIV), atualizados e } \\
\text { emitidos por empresa credenciada ao INMETRO. }\end{array}$ & \\
\hline 7 & C.N.H - categoria correspondente ao veículo & $\begin{array}{l}\text { Código de Trânsito Brasileiro - CTB e Lei No 9.503, de 23/09/97, } \\
\text { art.159. }\end{array}$ \\
\hline 8 & $\begin{array}{l}\text { Treinamento específico para condutores de veículos } \\
\text { transportadores de PP - Curso de } \\
\text { Movimentação Operacional de Produtos Perigosos } \\
\text { (MOPP) }\end{array}$ & $\begin{array}{l}\text { Art. } 15 \text { do Regulamento do Transporte Terrestre de Produtos } \\
\text { Perigosos; Resolução CONTRAN no 168/04. } \\
\text { Certificado do curso de formação do (s) condutor(es) motorista(s) } \\
\text { para as atividades de transporte de produtos ou resíduos perigosos } \\
\text { emitido por órgão competente; }\end{array}$ \\
\hline 9 & $\begin{array}{l}\text { Certificado de Capacitação para o transporte rodoviário } \\
\text { de produtos perigosos a granel, expedido pelo } \\
\text { INMETRO }\end{array}$ & $\begin{array}{l}\text { Art. 22, I do Regulamento do Transporte Terrestre de Produtos } \\
\text { Perigosos; Portaria n }{ }^{\circ} \text { 197/04 do INMETRO. }\end{array}$ \\
\hline 10 & Documento fiscal do produto transportado & $\begin{array}{l}\text { Art. 22, II do Regulamento do Transporte Terrestre de Produtos } \\
\text { Perigosos. }\end{array}$ \\
\hline 11 & $\begin{array}{l}\text { Ficha de emergência e envelope para o transporte } \\
\text { terrestre de produtos perigosos - Características, } \\
\text { dimensões e preenchimento }\end{array}$ & $\begin{array}{l}\text { Art. 22, III, alíneas "a" e "b" do Regulamento do Transporte } \\
\text { Terrestre de Produtos Perigosos; NBR } 7503 . \\
\text { Envelope e ficha de emergência, elaborados de acordo com as } \\
\text { normas NBR-7503 e } 7504 \text { da ABNT e demais documentos } \\
\text { previstos em lei. Essas fichas deverão conter todos os telefones } \\
\text { úteis, exigências técnicas, observações em caso de acidente } \\
\text { (gerador do resíduo, corpo de bombeiros, defesa civil polícia } \\
\text { rodoviária, órgão ambiental estadual e municipal). }\end{array}$ \\
\hline 12 & Tacógrafo & $\begin{array}{l}\text { Art. } 5^{\circ} \text { do Regulamento do Transporte Terrestre de Produtos } \\
\text { Perigosos. }\end{array}$ \\
\hline 13 & Simbologia - rótulos de risco e painel de segurança & $\begin{array}{l}\text { Art. } 2^{\circ} \text { do Regulamento do Transporte Terrestre de Produtos } \\
\text { Perigosos; NBR } 7500 .\end{array}$ \\
\hline 14 & $\begin{array}{l}\text { Conjunto de equipamentos para emergências no } \\
\text { transporte terrestre de produtos perigosos }\end{array}$ & $\begin{array}{l}\text { Art. } 3^{\circ} \text { do Regulamento do Transporte Terrestre de Produtos } \\
\text { Perigosos, NBR-9735. }\end{array}$ \\
\hline 15 & Plano de emergência e contingência & $\begin{array}{l}\text { Plano de emergência e contingência para o transporte de carga } \\
\text { perigosas; }\end{array}$ \\
\hline 16 & $\begin{array}{l}\text { Autorização Ambiental para o Transporte Interestadual } \\
\text { de Produtos Perigosos }\end{array}$ & $\begin{array}{l}\text { Caso o transporte de produtos ou resíduos perigosos venha a ser } \\
\text { transporte interestadual, torna-se obrigatório possuir Autorização } \\
\text { Ambiental para o Transporte Interestadual de Produtos Perigosos } \\
\text { emitida pelo Instituto Brasileiro do Meio Ambiente e dos Recursos } \\
\text { Naturais Renováveis (IBAMA) para cada um dos veículos de sua } \\
\text { frota. }\end{array}$ \\
\hline
\end{tabular}


O Quadro 8 estão referenciadas as principais documentações legais a serem analisadas pelos gestores junto a empresas prestadoras do serviço de transporte de resíduos perigosos.

\section{Discussão}

Nos termos da Lei 9.605/1998, que dispõe sobre as sanções penais e administrativas derivadas de condutas e atividades lesivas ao meio ambiente, a responsabilidade do gerador não termina no momento da retirada dos resíduos junto ao estabelecimento de saúde (Brasil, 1988b). A responsabilidade é solidária, entre o gerador e o prestador de serviços de coleta, tratamento e transporte até à disposição final. Dessa forma, faz-se necessário o acompanhamento por parte dos estabelecimentos de saúde dos processos das empresas contratadas para tais atividades. Com tal medida, busca-se evitar danos à saúde pública, ao meio ambiente e à segurança da população, tendo em vista que os veículos de transporte de resíduos de serviços de saúde circulam por áreas densamente povoadas. Considerando-se a responsabilidade solidária entre o gerador e o transportador, onde ambos podem ser penalizados caso ocorram danos ao meio ambiente durante a etapa de transporte, faz-se necessário que ações preventivas, como capacitação e orientações efetivas e periódicas, acompanhamento da rotina, consolidação de infraestrutura apropriada e controle médico efetivo das equipes de coleta sejam permanentemente gerenciados. Ainda assim, Silva (2020) relatou CETES a faixa de $47 \%$ de funcionários que não receberam treinamento para lidarem com esses resíduos em hospital público de Paragominas/PA, o que reflete a realidade nacional.

Segundo a Companhia de Tecnologia de Saneamento Ambiental (CETESB, n.d), cabe ao gerador contratar somente transportadoras aptas, possuidoras de Registro Nacional de Transportadores Rodoviários de Cargas (RNTRC) e que tenham veículos com equipamentos compatíveis com o estado físico e o tipo de embalagem dos resíduos a serem destinados, de modo a garantir a integridade e estanqueidade das embalagens e evitar o espalhamento do resíduo durante o transporte. Mediante essa recomendação, ao contratar empresas especializadas nos serviços de coleta e transporte externos de resíduos de serviços de saúde, o estabelecimento de saúde deve atentar-se quanto aos documentos legais obrigatórios e as condições impostas pelo órgão ambiental na concessão da licença de operação para a execução de tais atividades (CETESB, 1997).

Eventuais irregularidades na operação, manuseio e transporte rodoviário de cargas perigosas torna o gerador e o transportador sujeitos às penalidades previstas na Lei de Crimes ambientais $n^{\circ} 9.605 / 1998$, regulamentada pelos Decretos $n^{\circ}$ 6.514/2008 e n 6.686/2008 (Brasil, 1998b; 2008a; 2008b). Considerando-se os princípios de Direito Ambiental como o do Poluidor Pagador e de previsões legais expressas como a do $\S 1^{\circ}$ do artigo 14 da Lei 6.938/81 - Política Nacional do Meio Ambiente, o gerador dos resíduos permanece responsável pelas atividades de transporte de resíduos, e eventuais danos, ou acidentes destes decorrentes, mesmo após ter efetuado a destinação final por terceiros devidamente licenciados pelos órgãos ambientais competentes. $\mathrm{O}$ art. $14, \S 1^{\circ}$ da Lei $6.938 / 81$ estabelece:

... é o poluidor obrigado, independentemente da existência de culpa, a indenizar ou reparar os danos causados ao meio ambiente e a terceiros, afetados por sua atividade (Brasil, 1981, p.10).

A Constituição da República Federativa do Brasil de 1988, no art. 225, § $3^{\circ}$ estabelece que "As condutas e atividades consideradas lesivas ao meio ambiente sujeitarão os infratores, pessoas físicas ou jurídicas, a sanções penais e administrativas, independentemente da obrigação de reparar os danos causados" (Brasil, 1988a, p.147). As sanções administrativas previstas compreendem: advertência, multa simples, multa diária, suspensão parcial ou total das atividades, interdição do estabelecimento e/ou restritiva de direitos (cancelamento da licença etc.). O art. 54. da Lei 9.605/1998 define as seguintes penas em caso de infração ambiental (Brasil, 1998b, p.11):

Art. 54. Causar poluição de qualquer natureza em níveis tais que resultem ou possam resultar em danos à saúde humana, ou que provoquem a mortandade de animais ou a destruição significativa da flora: Pena - reclusão, de um a 
quatro anos, e multa.

$\S 1^{\circ} \mathrm{Se}$ o crime é culposo: Pena - detenção, de seis meses a um ano, e multa.

$\S 2^{\circ}$ Se o crime:

I - Tornar uma área, urbana ou rural, imprópria para a ocupação humana;

II - Causar poluição atmosférica que provoque a retirada, ainda que momentânea, dos habitantes das áreas afetadas , ou que cause danos diretos à saúde da população;

III - Causar poluição hídrica que torne necessária a interrupção do abastecimento público de água de uma comunidade;

IV - Dificultar ou impedir o uso público das praias;

V - Ocorrer por lançamento de resíduos sólidos, líquidos ou gasosos, ou detritos, óleos ou substâncias oleosas, em desacordo com as exigências estabelecidas em leis ou regulamentos: Pena - reclusão, de um a cinco anos.

As auditorias ambientais são um importante instrumento de gestão. O conceito formulado por Grizzi (2004, p.159) trata as auditorias ambientais como "...verdadeiros instrumentos de controle ambiental". Consubstanciam-se em um processo que tem por fim verificar a atividade econômica desenvolvida, frente aos critérios e escopos eleitos para realização da auditoria, ocasional ou periodicamente. A auditoria ambiental mostra a "fotografia" da empresa em relação aos critérios e escopos eleitos, ao verificar, por exemplo, em uma auditoria jurídica de responsabilidade e de conformidade legal, o cumprimento das normas ambientais e a responsabilidade de cada parte envolvida. As evidências obtidas, por meio da análise dos documentos, entrevistas e inspeções junto as áreas devem ser comparadas com a legislação aplicável de modo a obter um levantamento da gestão ambiental da empresa auditada.

Para que cumpra adequadamente o seu papel, uma Auditoria Ambiental deve ser sistemática, completa e detalhada, onde cada aspecto ambiental e área devem ser avaliadas segundo uma metodologia específica. De acordo com Norma ABNT NBR ISO 19011:2018 Versão Corrigida:2019, ao término das atividades de verificação, faz-se necessário que seja documentada de forma que os registros facilitem a resolução dos problemas encontrados e sirvam de base de comparação com auditorias futuras. Importante que sejam realizadas em intervalo regulares e que seja objetiva, buscando obtenção de evidências ligadas ao desempenho e aos aspectos ambientais, visando avaliar o grau de conformidade dos critérios definidos a priori (ABNT, 2018d).

\section{Considerações Finais}

As instituições de serviços de saúde podem contribuir significativamente para o processo de gestão ambiental a partir do gerenciamento de seus resíduos sólidos com uma visão global e ações locais. Deve-se ter como base normas internas, legislação vigente e a busca de informações, ampliando as discussões e medidas conjuntas para uma gestão dos resíduos sólidos, envolvendo ações de proteção ambiental interna e externa. Assim, a colaboração de todos os funcionários é essencial na busca pela segurança do paciente, do profissional e do meio ambiente.

Tendo em vista o cenário de RSS no Brasil e a relevância do gerenciamento de resíduos para as instituições de saúde, para a sociedade e para o meio ambiente, considera-se extremamente importante a contribuição que os hospitais podem dar ao meio ambiente ao se atentarem para o acompanhamento mais efetivo das etapas externas de gestão dos resíduos de serviços de saúde. Como proposição para estudos futuros, recomenda-se a elaboração de novas pesquisas visando a elaboração de checklists para outros grupos de resíduos de serviços de saúde, tendo em vista a relevância do assunto para o setor de saúde.

\section{Referências}

Associação Brasileira de Normas Técnicas. (1990). NBR 11875. Incineração de resíduos sólidos perigosos: Padrões de desempenho - Procedimento.

Associação Brasileira de Normas Técnicas. (1992). NBR 12235. Armazenamento de resíduos sólidos perigosos: Procedimento.

Associação Brasileira de Normas Técnicas. (2003). NBR 14015. Gestão ambiental: Avaliação ambiental de locais e organizações (AALO). Associação Brasileira de Normas Técnicas. (2004). NBR 10004: Resíduos Sólidos: Classificação. 
Associação Brasileira de Normas Técnicas. (2008). NBR 9191. Sacos plásticos para acondicionamento de lixo: Requisitos e métodos de ensaio.

Associação Brasileira de Normas Técnicas. (2013a). NBR 12809. Resíduos de serviços de saúde: Gerenciamento de resíduos de serviços de saúde intraestabelecimento.

Associação Brasileira de Normas Técnicas. (2013b). NBR 12807. Resíduos de serviços de saúde: Terminologia.

Associação Brasileira de Normas Técnicas. (2013c). NBR 16173. Transporte terrestre de produtos perigosos: Carregamento, descarregamento e transbordo a granel e embalados - Capacitação de colaboradores.

Associação Brasileira de Normas Técnicas. (2014). NBR 16725. Resíduo químico: Informações sobre segurança, saúde e meio ambiente-Ficha com dados de segurança de resíduos químicos (FDSR) e rotulagem.

Associação Brasileira de Normas Técnicas. (2015a). NBR 16434. Amostragem de resíduos sólidos, solos e sedimentos: Análise de compostos orgânicos voláteis $(\mathrm{COV})$ - Procedimento.

Associação Brasileira de Normas Técnicas. (2015b). NBR 14064. Errata 1: Transporte rodoviário de produtos perigosos: Diretrizes do atendimento à emergência.

Associação Brasileira de Normas Técnicas. (2015c). NBR ISO 14001. Sistemas de gestão ambiental. Requisitos com orientações para uso.

Associação Brasileira de Normas Técnicas. (2015d). NBR 14619. Transporte terrestre de produtos perigosos: Incompatibilidade química.

Associação Brasileira de Normas Técnicas. (2015e). NBR 14064. Versão Corrigida: 2015. Transporte rodoviário de produtos perigosos. Diretrizes do atendimento à emergência.

Associação Brasileira de Normas Técnicas. (2016). NBR 12808. Resíduos de serviços de saúde: Classificação.

Associação Brasileira de Normas Técnicas. (2017). NBR 13334. Contentores metálicos 0,8 m3 a 1,6 m3 para coleta de resíduos sólidos por coletorescompactadores de carregamento traseiro - Requisitos para fabricação e utilização.

Associação Brasileira de Normas Técnicas. (2018a). NBR 16701. Implementos rodoviários - Contentores fixos para resíduos Parte 1: Contentores com capacidade de até 3200 L com tampas para dispositivos de elevação do tipo suporte giratório e suporte giratório duplo - Dimensões e projeto.

Associação Brasileira de Normas Técnicas. (2018b). NBR 16699. Implementos rodoviários: Veículos coletores compactadores de resíduos sólidos e seus dispositivos de elevação de contentores Parte 1: Carregamento traseiro.

Associação Brasileira de Normas Técnicas. (2018c). NBR 16699. Implementos rodoviários - Veículos coletores compactadores de resíduos sólidos e seus dispositivos de elevação de contentores Parte 2: Carregamento lateral.

Associação Brasileira de Normas Técnicas. (2018d). NBR ISO 19011. 2018. Versão Corrigida: 2019. Diretrizes para auditoria de sistemas de gestão.

Associação Brasileira de Normas Técnicas. (2019). NBR 14652. Implementos rodoviários: Coletor transportador de resíduos de serviços de saúde Requisitos de construção e inspeção.

Associação Brasileira de Normas Técnicas. (2020a). NBR 7500. Identificação para o transporte terrestre, manuseio, movimentação e armazenamento de produtos.

Associação Brasileira de Normas Técnicas. (2020b). NBR 14599. Implementos rodoviários- Requisitos de segurança para coletores-compactadores de resíduos sólidos.

Associação Brasileira de Normas Técnicas. (2020c). NBR 12810: Resíduos de serviços de saúde, Gerenciamento extraestabelecimento, Requisitos.

Associação Brasileira de Normas Técnicas. (2020d). NBR 16849. Resíduos sólidos urbanos para fins energéticos - Requisitos.

Associação Brasileira de Normas Técnicas. (2020e). NBR 7503. Transporte terrestre de produtos perigosos: Ficha de emergência- Requisitos mínimos.

Associação Brasileira de Normas Técnicas. (2020f). NBR 12982. Transporte terrestre de produtos perigosos: Procedimentos para serviços de limpeza ou de descontaminação.

Associação Brasileira de Normas Técnicas. (2020g). NBR 7501. Transporte terrestre de produtos perigosos: Terminologia.

Associação Brasileira de Normas Técnicas. (2021a). NBR 13853. Recipientes para resíduos de serviços de saúde perfurantes ou cortantes: Requisitos e métodos de ensaio Parte 1: Recipientes descartáveis.

Associação Brasileira de Normas Técnicas. (2021b). NBR 15480. Transporte rodoviário de produtos perigosos: Programa de gerenciamento de risco e plano de ação de emergência.

Associação Brasileira de Normas Técnicas. (2021c). NBR 13221. Transporte terrestre de produtos perigosos: Resíduos.

Brasil. (1981). Lei. 6938 de 31 de agosto de 1981. Dispõe sobre a Política Nacional do Meio Ambiente, seus fins e mecanismos de formulação e aplicação, e dá outras providências. https://www.planalto.gov.br/ccivil_03/Leis/L6938.htm.

Brasil. (1988a). Constituição da República Federativa do Brasil. 1988. http://www.planalto.gov.br/ccivil_03/constituicao/constituicao.htm. 
Brasil. (1988b). Lei. 9605 de 12 de fevereiro de 1988. Dispõe sobre as sanções penais e administrativas derivadas de condutas e atividades lesivas ao meio ambiente, e dá outras providências. http://www.planalto.gov.br/ccivil_03/LEIS/L9605.htm.

Brasil. (1990) Conselho Nacional do Meio Ambiente. Resolução $n^{o} 1$, de 8 de março de 1990. Dispõe sobre critérios de padrões de emissão de ruídos decorrentes de quaisquer atividades industriais, comerciais, sociais ou recreativas, inclusive as de propaganda política. http://www.suape.pe.gov.br/images/publicacoes/resolucao/Resolu\%C3\%83\%C2\%A7\%C3\%83\%C2\%A3o_CONAMA_001_1990.pdf.

Brasil. (1990) Conselho Nacional do Meio Ambiente. Resolução $n^{o} 3$, de 28 de junho de 1990. Dispõe sobre padrões de qualidade do ar, previstos no PRONAR. https://www.ibama.gov.br/sophia/cnia/legislacao/MMA/RE0003-280690.PDF.

Brasil. (1989) Conselho Nacional do Meio Ambiente. Resolução no 5, de 15 de junho de 1989. Dispõe sobre o Programa Nacional de Controle da Poluição do $\mathrm{Ar}$ - PRONAR. https://www.bmn.com.br/plan-leg/ma/fed/resol/conama05-89.pdf.

Brasil. (1990) Conselho Nacional do Meio Ambiente. Resolução $n^{\circ}$ 8, de 06 de dezembro de 1990. Dispõe sobre o estabelecimento de poluentes no ar para processos de combustão externas de fontes de poluição. http://www.ibama.gov.br/sophia/cnia/legislacao/MMA/RE0008-061290.PDF.

Brasil. (2002a) Conselho Nacional do Meio Ambiente. Resolução nº306, de 05 de julho de 2002. Estabelece os requisitos mínimos e o termo de referência para realização de auditorias ambientais. http://www2.mma.gov.br/port/conama/legiabre.cfm?codlegi=306.

Brasil. (2002b). Conselho Nacional do Meio Ambiente. Resolução $n^{o}$ 316, de 29 de outubro de 2002. Dispõe sobre procedimentos e critérios para o funcionamento de sistemas de tratamento térmico de resíduos. http://www2.mma.gov.br/port/conama/legiabre.cfm?codlegi=338

Brasil. (2006). Conselho Nacional do Meio Ambiente. Resolução $n^{\circ} 382$, de 26 de dezembro de 2006. Estabelece os limites máximos de emissão de poluentes atmosféricos para fontes fixas. http://www2.mma.gov.br/port/conama/res/res06/res38206.pdf

Brasil. (2004). Ministério dos Transportes. Agência Nacional de Transportes Terrestre. Resolução n. 420, de 12 de fevereiro de 2004. Aprova as Instruções Complementares ao Regulamento do Transporte Terrestre de Produtos Perigosos. http://www.cetsp.com.br/media/20041/resolucao420_v3_20080123.pdf.

Brasil. (2005). Conselho Nacional do Meio Ambiente. Resolução $n^{\circ} 358$, de 29 de abril de 2005. Dispõe sobre o tratamento e a disposição final dos resíduos dos serviços de saúde e da outra providencias. http://www2.mma.gov.br/port/conama/legiabre.cfm?codlegi=462.

Brasil. (2016). Ministério dos Transportes. Agência Nacional de Transportes Terrestre. Resolução n. 5232, de 14 de dezembro de 2016. Aprova as Instruções Complementares ao Regulamento Terrestre do Transporte de Produtos Perigosos, e dá outras providências. https://www.in.gov.br/materia//asset_publisher/Kujrw0TZC2Mb/content/id/24783215.

Brasil. (2018). Agência Nacional de Vigilância Sanitária. Resolução da Diretoria Colegiada $n^{o} 222$, de 28 de março de 2018 . Dispõe sobre o Regulamento Técnico para o gerenciamento de Resíduos de Serviços de Saúde. https://www.gov.br/anvisa/ptbr/centraisdeconteudo/publicacoes/servicosdesaude/publicacoes/rdc-222-de-marco-de-2018-comentada.pdf/view.

Brasil. (2019). Ministério dos Transportes. Agência Nacional de Transportes Terrestre. Resolução n. 5848, de 25 de junho de 2019. Atualiza o Regulamento para o Transporte Rodoviário de Produtos Perigosos e dá outras providências. https://www.in.gov.br/web/dou/-/resolucao-n-5.848-de-25-de-junho-de-2019173020360

Brasil. (2019). Ministério dos Transportes. Agência Nacional de Transportes Terrestre. Decreto n. 6514, de 22 de julho de 2008. Dispõe sobre as infrações e sanções administrativas ao meio ambiente, estabelece o processo administrativo federal para apuração destas infrações, e dá outras providências. http://www.planalto.gov.br/ccivil_03/_ato2007-2010/2008/decreto/d6514.htm

Brasil. (2019). Ministério dos Transportes. Agência Nacional de Transportes Terrestre. Decreto n. 6686, de 10 de dezembro de 2008. Altera e acresce dispositivos ao Decreto no 6.514, de 22 de julho de 2008, que dispõe sobre as infrações e sanções administrativas ao meio ambiente e estabelece o processo administrativo federal para apuração destas infrações. http://www.planalto.gov.br/ccivil_03/_Ato2007-2010/2008/Decreto/D6686.htm

Companhia de Tecnologia de Saneamento Ambiental (CETESB). (n.d.). Plano de ação de emergência - PAE. https://cetesb.sp.gov.br/emergenciasquimicas/tipos-de-acidentes/rodovias/plano-de-acao-de-emergencia-pae/.

Fachin, O. (2001). Fundamentos de metodologiasSaraiva.

Gondim, S. M. G. (2003). Grupos focais como técnica de investigação qualitativa: desafios metodológicos. Paidéia, 12(24), 149-161

Grizzi, A.L.E. (2003). Direito ambienta, Auditorias ambientais e atividades econômicas. Direito Ambiental: enfoques variados. Lemos \& Cruz.

Jones, D. G. (1997). Auditoria ambiental. UERJ.

Machado, P. A. L. (2003). Direito ambiental brasileiro. (11a. ed.) Malheiros.

Rey, F. L. G. (2005). Pesquisa qualitativa e subjetividade: os processos de construção da informação. Pioneira Thomson Learning. 